\title{
Addressing oral health inequalities in the United Kingdom - the impact of devolution on population-based fluoride policy
}
IN BRIEF
- Improvement in UK children's oral health has been remarkable since fluoridated toothpaste became widely available in the early 1970s.
- The burden of dental decay now rests on the most socially disadvantaged children.
- Describes approaches to oral health improvement in the home countries since devolution and their impact.

\author{
I. G. Chestnutt ${ }^{1}$
}

The front covers of the current volume of the British Dental Journal (Volume 215) feature drawings by children participating in the Welsh national oral health improvement programme - Designed to Smile. This programme involves 78,350 children in the Principality, who are deemed at greatest risk of tooth decay, participating in daily toothbrushing in 1,211 nurseries and schools. It mirrors the Childsmile 2 programme in Scotland. Since devolution in 1999, approaches to oral health improvement across the United Kingdom have diverged. This article considers the way in which population-based policies with regards to fluoride use have varied between countries.

Improvements in the oral health of children in the United Kingdom in the past 40 years have been remarkable. In 1973 the average 15-year-old in England and Wales had 8.4 decayed, missing or filled permanent teeth and $97 \%$ of the population were affected by dental caries. ${ }^{3}$ By 2003, the average British 15-year-old had 1.9 teeth with obvious decay experience and 49\% of the population were affected. ${ }^{4}$ However, these figures, being population averages, mask an important fact. While many more children are now free from dental caries, the disease has become increasingly concentrated in so called high-risk groups, and the burden of dental decay now falls to a great extent on poor children. In common with all chronic, lifestyle associated diseases, dental caries is closely linked to social and economic deprivation.

Inequalities in health and oral health are one of the great challenges remaining in health improvement. Changing lifestyles and life circumstances are key to decreasing the social gradient in health. At times of economic constraint this poses particular challenges. Upstream, common risk

${ }^{1}$ Professor and Hon Consultant in Dental Public Health, Cardiff University Dental School, Heath Park, Cardiff, CF14 4XY

${ }^{*}$ Correspondence to: Professor Ivor Chestnutt Email: chestnuttig@cardiff.ac.uk

Accepted 9 May 2013

DOI: $10.1038 /$ sj.bdj.2013.626

${ }^{\bullet}$ British Dental Journal 2013; 215: 11-12 factor approaches (to use the jargon) play a crucial part in addressing oral health inequalities. Any action which encourages a change in behaviour such as a ban on vending machines in schools or a tax on sugared beverages will benefit oral health, as well as addressing wider health issues such as diabetes and obesity.

The great improvements in oral health referred to above can be attributed in large part to the introduction and use of fluoride toothpaste, which first became widely available in the United Kingdom in the early 1970s. The question is therefore, what can be done to ensure that the teeth of children in deprived communities come into contact with fluoride sufficiently often to stave off the cariogenic challenge of a diet in which sugar is consumed frequently and in large amounts?

Following devolution, the course of actions taken by the various health departments around the United Kingdom with regards to oral health improvement and in particular fluoride policy has differed. Without doubt, the single biggest step that could be taken to make available fluoride to deprived communities is targeted fluoridation of the public water supply. In England, about six million people, mainly in the West Midlands and the North East, have this benefit. There are currently no artificially fluoridated water supplies in Scotland, Wales or Northern Ireland. The Department of Health in England, in their
1998 White Paper, strongly supported water fluoridation as a means of addressing oral health inequalities. ${ }^{5}$ This policy was heavily promoted during the tenure of the last government and culminated in the decision by South Central Strategic Health Authority to fluoridate part of the water supply in Hampshire in 2009. And yet, as a result of legal challenges, organisational change and the general difficulties associated with fluoridation, no new water fluoridation schemes have been introduced in England, in spite of support from the very highest political level. ${ }^{6}$

Scotland has a proud but unsuccessful history of pursuing water fluoridation. The infamous Strathclyde case in the early 1980s, in which an edentulous grandmother litigated against Strathclyde Regional Council in the Scottish High Court, blocked efforts to fluoridate the public water supply. ${ }^{7}$ A further attempt at fluoridation by Glasgow City Council in 1990 similarly ended in failure. By the mid-1990s, only 42\% of Scottish children were without obvious decay by the time they started school. ${ }^{8}$ As a result, a different approach was taken by the Scottish Health Boards. A regime of daily brushing in nursery schools and schools was introduced. By increments this programme has grown. In its Dental Action Plan ${ }^{9}$ the newly devolved Scottish Government officially recognised the benefits of fluoridation but opted instead to pursue school-based 
brushing schemes through their Childsmile programme. This has acted as the Scots' means of getting fluoride into contact with the teeth of those youngsters at greatest risk of decay.

Data from the national dental epidemiological programme in Scotland have shown that the proportion of children in Primary 1 without obvious dental decay rose from $42.3 \%$ in 1996 to $67 \%$ in $2012^{8}$ - a remarkable turnaround for a nation notorious for its sweet tooth. Macpherson and colleagues have recently published a detailed analysis of the Scotland-wide school toothbrushing scheme. ${ }^{10}$ They concluded that the changes seen in the oral health of Scottish youngsters is likely to be due, to a large extent, to the introduction and uptake of nursery school toothbrushing programmes. Furthermore they reported that this improvement came about in the face of flat-lining trends in general child health indicators. ${ }^{10}$

So what about Wales? Historically, children's oral health in Wales was always better than that of their Celtic cousins north of Hadrian's wall. ${ }^{11}$ However, the 2005/6 surveys coordinated by the British Association for the Study of Community Dentistry demonstrated that child oral health in Wales had, for the first time, fallen behind that in Scotland. ${ }^{12}$ The position of the Welsh Government on water fluoridation is that while it recognises the significant health benefits and potential to address inequalities, it has no plans to introduce fluoridation. ${ }^{13}$ Given developments in Scotland and the need to increase access to fluoride of at risk children, in 2008 the Welsh Government launched Designed to Smile. Targeted at schools attended by children at greatest risk of dental caries and modelled on Childsmile, this programme now has in excess of 78,000 children participating in daily brushing in nursery and infant schools. In addition to brushing in schools, children are provided with toothbrushes and toothpaste to use at home.

In the UK league table of oral health, Northern Ireland has been a long time possessor of 'the wooden spoon', and fares much worse than the Irish Republic,
$71 \%$ of whose citizens benefit from water fluoridation. ${ }^{14}$

On 1 April 2013, responsibility for improving health in England transferred to local authorities. Given their wide powers and responsibilities for schools and indeed the wider environment, this represents a great opportunity to focus on oral health inequalities in children. Banning vending machines in schools, mandating fruit tuck shops and promotion of 'water in school' programmes as well as promotion of a locally appropriate fluoride policy are all opportunities open to local authorities.

School toothbrushing schemes are complex to organise and administer. The potential savings associated with the improved dental health arising remains unknown. ${ }^{10}$ However, in the absence of fluoride, health education alone does little to improve oral health in a sustainable fashion. ${ }^{15}$ As Davies and Bridgman so aptly put it in a previous commentary in this Journal, ${ }^{16}$ 'the days of colouring in carrots have gone'. Visits of 'Harry the Horse' and his big-toothed puppet friends and nursery songs about teeth go down well with children and their teachers. They are good at raising awareness, but do nothing to get fluoride into contact with teeth. Encouraging toothbrushing in children who live in a household where there is no toothpaste is a waste of time. I will never forget the child who once told me she hadn't brushed her teeth because her brother had gone to stay overnight with their dad and had taken the toothbrush. Programmes like Designed to Smile and Childsmile facilitate home toothbrushing in children who might otherwise not have access to a toothbrush or toothpaste.

Regression to traditional approaches to dental health education must be avoided. There is much to be learned within the UK by sharing experiences of the different approaches to improving oral health since devolution in 1999. The National Institute for Health and Clinical Excellence has been commissioned to develop evidence based guidance for local authorities on improving oral health. This should direct local authorities to evidence-based policies that fit the needs and wishes of local communities.
It is to be hoped that the great strides made in improving oral health in the last quarter of the twentieth century can be continued. The programmes described here have the potential to improve the oral health of children from socioeconomically deprived areas in the UK - children who now carry the burden of a disease which is largely determined by environmental and behavioural factors and should be totally preventable.

1. Designed to Smile. www.designedtosmile.co.uk/ home.html (accessed April 2013)

2. Childsmile. www.child-smile.org.uk (accessed April 2013).

3. Todd J E. Children's dental health in England and Wales 1973. London: Office of Population Census and Surveys, 1975.

4. Pitts N B, Chestnutt I G, Evans D, White D, Chadwick B Steele J G. The dentinal caries experience of children in the United Kingdom, 2003. Br Dent J 2006; 200: 313-320.

5. Department of Health. Saving lives: our healthie nation. London: Department of Health, 1999.

6. Hansard. Prime Minister's Questions 26 March 2008 PMQ Column 183. London: Hansard 2008. Online information available at www.publications.parliament.uk (accessed April 2013).

7. Court of Session. Opinion of Lord Jauncey in causa Mrs Catherine McColl (A P) against Strathclyde Regional Council. Edinburgh. Court of Session 1982.

8. Information Services Division, NHS National Services Scotland. National Dental Inspection Programme 2012. Online information available at http: //www.isdscotland.org/Health-Topics/DentalCare/Publications/20121127/20121127DentaINDIPR eport.pdf?41798037291 (accessed April 2013).

9. The Scottish Government. An action plan for improving oral health and modernising NHS dental services in Scotland. Edinburgh: The Scottish Government 2005. Online information available at www.scotland. gov.uk/Publications/2005/03/20871/54815 (accessed April 2013).

10. Macpherson L M D, Anopa Y, Conway D I, McMahon A D. National supervised toothbrushing programme and tooth decay in Scotland. J Dent Res 2013; 92: 109-113.

11. Pitts N B, Evans D J, Nugent $Z$ J. The dental caries experience of 5 yearold children in Great Britain. Surveys coordinated by the British Association for the Study of Community Dentistry in 1999/2000. Community Dent Health 2001; 18: 49-55.

12. Pitts N B, Boyles J, Nugent Z J, Thomas N, Pine C M The dental caries experience of 5yearold children in Great Britain (2005/6). Surveys coordinated by the British Association for the Study of Community Dentistry. Community Dent Health 2007; 24: 59-63.

13. Welsh Government Together for Health: a national oral health plan for Wales 2013-2018. Online information available at http://wales.gov.uk/docs/phhs/ publications/130318oralhealthplanen.pdf (accessed April 2013).

14. Whelton $H_{1}$ Crowley E, O'Mullane D, Donaldson $\mathrm{M}$, Cronin M, Kelleher V. Dental caries and enamel fluorosis among the fluoridated population in the Republic of Ireland and non fluoridated population in Northern Ireland in 2002. Community Dent Health 2006; 23: 37-43.

15. Kay E, Locker D. A systematic review of the effectiveness of health promotion aimed at improving oral health. Community Dent Health 1998; 15: 132-144.

16. Davies G, Bridgman C. Improving oral health among schoolchildren - which approach is best? Br Dent J 2011; 210: 59-61. 